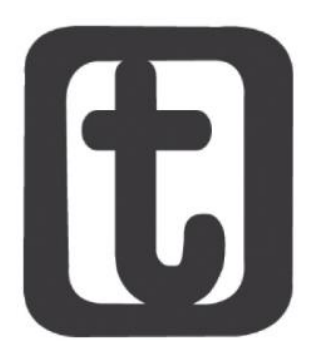

\title{
ABUSO SEXUAL: FORMAÇÃO PROFISSIONAL, CONDIÇÕES DE ENFRENTAMENTO DA PROTEÇÃO SOCIAL ESPECIAL E O ADOECIMENTO DO PROFISSIONAL QUE ATUA NO ATENDIMENTO ÀS VÍTIMAS
}

\author{
Sexual abuse: vocational training, conditions for facing special social protection and the \\ advocacy of the professional who cares for the victims
}

\section{Elizabeth da Silva Alcoforado*

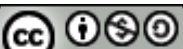

\section{RESUMO}

O presente artigo é fruto da tese de doutorado em sociologia/UFPB - O poder nos muros do silêncio: abuso sexual, segredo e família, defendida em 2016. As vítimas de violência sexual nas unidades de saúde e de assistência são sempre acolhidas por uma equipe multidisciplinar. A multiplicidade de olhares para uma mesma questão - o abuso sexual favorece a compreensão deste problema como multifacetado. Como pontuou Azevedo e Guerra (2007), a vítima de abuso sexual apresenta-se como uma síntese de comorbilidade, ou seja, a vítima nunca se apresenta apenas com uma única modalidade de violência, mas como uma síntese de modalidade de violência intrafamiliar que será revelada no contato e na escuta qualificada da equipe multidisciplinar. A revelação da violência sexual, mediante relato da vítima junto aos profissionais qualificados, possibilita também a exposição de toda uma dinâmica da violência doméstica. Neste sentido, a atuação em rede é um ponto crucial, visto que várias demandas se apresentam, requerendo com isso que o trabalho seja fortalecido entre os técnicos de atendimento direto, como também com a equipe de referência e contra referência. Trabalhar com a dor do outro não representa uma tarefa fácil para as equipes multidisciplinares no setor de saúde e assistência social. As dificuldades de operacionalizar as ações por limitações institucionais, de formação, de apoio e falta de capacitação adequada, muitas vezes, leva a própria equipe a buscar formas criativas para suportar o peso do cotidiano permeado por histórias de violências.

\section{PALAVRAS-CHAVE}

Violência sexual intrafamiliar. Equipe multidisciplinar. Adoecimento profissional.

\footnotetext{
* Assistente social. Doutora em sociologia (UFPB). Professora da Universidade Federal de Pernambuco (UPE, Recife, Brasil). Av. Prof. Moraes Rego, 1235, Cidade Universitária, Recife (PE), CEP.: 50670-901. E-mail: <elizabeth.alcoforado@upe.br>.ORC ID: <https://orcid.org/0000-0003-0146-4803>.
} 


\section{asusosesvatempordilis}

\section{ABSTRACT}

This article is the result of the doctoral thesis in sociology/UFPB - The power in the walls of silence: sexual abuse, secrecy and family, defended in 2016. Victims of sexual violence at health and care facilities are always hosted by a multidisciplinary team. The multiplicity of views on the same issue - sexual abuse - favors the understanding of this problem as multifaceted. As Azevedo and Guerra (2007) pointed out, the victim of sexual abuse presents itself as a synthesis of comorbidity, that is, the victim never presents with only a single modality of violence, but as a synthesis of intrafamily violence modality that will be revealed in the contact and qualified listening of the multidisciplinary team. The disclosure of sexual violence, through reporting the victim to the qualified professionals, also allows exposure of a whole dynamics of domestic violence. In this sense, networking is a crucial point, since several demands arise, requiring that the work be strengthened among the direct service technicians, as well as with the reference and counter staff. Working with each other's pain is not an easy task for multidisciplinary teams in the health and social care sector. The difficulties of operationalizing the actions due to institutional limitations, training, support and lack of adequate training often leads the team to seek creative ways to bear the weight of daily life permeated by stories of violence.

\section{KEYWORDS}

Sexual intrafamily violence. Multidisciplinary team. Occupational sickness

Submetido em: 4/5/2018.

Aceito em: 28/5/2018.

\section{ABORDAGEM TEÓRICA E LEGAL}

A necessidade de atendimento às vítimas de abuso sexual, no Brasil, teve sua maior visibilidade a partir da política de proteção social especial, no âmbito da assistência social. A definição de um marco legal tomando a Lei Orgânica da Assistência Social (LOAS), a Política Nacional de Assistência Social (PNAS) não só se apresentam como uma intervenção no marco legal, mas também, na fomentação de estudos e diretrizes de formação preconizada pela Norma de Operacionalização Básica de Recursos Humanos (NOB-RH) que define o atendimento especializado mediante uma equipe multidisciplinar para à atuação frente ao fenômeno.

A violência contra crianças e adolescentes é um fenômeno que se apresenta desde o início da humanidade. Segundo Ferreira (2002):

Relatos de filicídios, de maus-tratos, de negligência, de abandonos, de abusos sexuais, são encontrados na mitologia ocidental, em passagens bíblicas, em rituais de iniciação ou de passagem para a idade adulta, fazendo parte da história cultural da humanidade (FERREIRA, 2002, p. 27).

Este tipo de violência pode ocorrer nos espaços intra e extrafamiliares, denominando-se, respectivamente de violência doméstica e violência urbana.

No entendimento de Guerra (1998), 
[...] a violência doméstica contra crianças e adolescentes representa todo ato de omissão, praticado por pais, parentes ou responsáveis, contra crianças e/ou adolescentes que - sendo capaz de causar dano físico, sexual e/ou psicológico à vítima - implica, de um lado uma transgressão do poder/dever de proteção do adulto e, de outro, uma coisificação da infância, isto é, uma negação do direito que crianças e adolescentes têm de ser tratados como sujeitos e pessoas em condição peculiar de desenvolvimento (GUERRA, 1998, p. 32-33).

A violência intra e extrafamiliar caracteriza-se pela manifestação da violência física, sexual, psicológica, negligência e o trabalho infantil. Historicamente, a violência física tem sido privilegiada nos estudos socioantropológicos, como a forma característica da violência, embora travestida de medida educativa.

A proteção à criança e ao adolescente, desde a Constituição Federal de 1988, começa a ter mais evidência no cenário nacional, configurando-se nas legislações de políticas setoriais (assistência social, educação, saúde, segurança), na confecção de planos de intervenção e se efetivando a partir da implantação de aparelho de gestão que proporciona o atendimento desta população específica para além do caráter punitivo, desenvolvendo ações preventivas cuja tônica orientadora seja a proteção social.

As legislações anteriores à CF/88 que orientavam os cuidados à infância foram todas forjadas dentro de uma lógica punitiva coercitiva. Como pontua Arrazola (1997), o menor sempre foi visto como perigo, cabendo a necessidade de criação de instrumentos de gestão que reproduziam e reforçavam estereótipos que associavam a pobreza e a negritude a elementos de perigo.

Após a CF/88, ocorre uma mudança significativa no olhar para esta faixa etária, fato demonstrado também no trato legal de situação irregular em que a infância passa a ser percebida como necessária de atendimento, a partir de uma proteção integral o que "[...] produziu um reordenamento das prioridades e valores sociais, em direção ao resgate da infância e adolescência protegidas como valor social” (AMARO, 2011, p. 38).

A perspectiva da atenção integral levou a uma revisão das políticas públicas no sentido de sua maior intersetorialidade para atender às demandas apresentadas pela população cuja fase geracional agrega a infância e juventude.

No âmbito da assistência social, a Lei Orgânica da Assistência Social (LOAS) (BRASIL, 1993), em seus artigos $6^{\circ} \mathrm{A}$ e $6^{\circ} \mathrm{B}$, aponta para a garantia da proteção social em seus diferentes graus de atendimento: proteção social básica e a proteção social especial, cabendo a ambas serem ofertadas por uma rede socioassistencial na qual cabe participação do poder público e da iniciativa privada.

Para nosso estudo, percebemos que os casos de abuso sexual são abordados no nível de proteção social especial e entende-os como sendo:

[...] um conjunto de serviços, programas e projetos que têm por objetivo contribuir para a reconstrução de vínculos familiares e comunitários, a defesa de direito, o fortalecimento das potencialidades e aquisições e a proteção de

Temporalis, Brasília (DF), ano 18, n. 35, jan./jun. 2018. 


\title{
asusosesvatempordilis
}

famílias e indivíduos para o enfrentamento das situações de violações de direitos (BRASIL, 2011, não paginado).

No Art. $6^{\circ} \mathrm{C}$ da LOAS $/ 93^{1}$ estão definidas as particularidades das unidades de gestão por tipo específico de proteção social. Para os casos específicos de violações de direito cujo vínculo familiar esteja comprometido são ofertados unidades de Centro de Referência da Assistência Social (CREAS). Conforme o parágrafo segundo da legislação em tela o CREAS.

Hoje, o Brasil conta com cerca de 2.372 unidades de CREAS em todo território nacional, ocorrendo, segundo o Censo SUAS 2014, um crescimento considerável de unidades de gestão para a proteção social especial. Em 2009, o país contava com 1200 unidades. Destaca-se, dentre as regiões do território nacional, a região Nordeste com o maior número de unidade de gestão, contabilizando, em 2014, 914 unidades de CREAS.

No que se refere a estas unidades o atendimento poderá ser de abrangência aos casos de média e alta complexidade e composto por uma equipe multidisciplinar formada por assistentes sociais, psicólogos, advogados, pedagogos, além de profissionais de nível médio.

\section{O PROFISSIONAL E A ATO DE TESTEMUNHO EXTERNO: COMPREENDER A VIOLÊNCIA SUBJETIVA NOS ESPAÇOS DOMÉSTICOS}

Velázquez (2012), em seu capítulo sobre os testemunhos de atos violentos, ressalta como o trabalho direto com vítimas de violência possibilita um comprometimento físico e mental. "Contemplar la calidad de vida laboral está intimamente vinculado con el cuidado de la salud de quienes trabajan en el tema" (VELÁZQUEZ, 2012, p. 131)².

Tal envolvimento do trabalhado, com relatos, recomposição de cenas traumáticas, expressões de sentimentos dúbios e confusos das vítimas, culpabilização das mesmas diante da violência, tem um efeito na subjetividade do profissional. Esses efeitos foram analisados por Velázquez (2012) e são denominados por ela de efeitos de ser testemunho.

\begin{abstract}
En estos casos, la acumulación de esas experiencias puede tener un efecto traumático al superar la capacidad de tolerancia psíquica de un sujeto, dando lugar al surgimento de procesos compeljos. Es decir, a consecuencia del encuentro con situaciones de alto impacto emocional que puede promover el relato de alguna víctma se suele originar angustia, a partir de la que se pueden organizar fantasías, temores y ansiedades que pondrán en funcionamiento mecanismos defensivos con la finalidad de evitar o neutralizar las consecuencias que pueden afectar al profesional así como condicionar el desempeño laboral

(VELÁZQUEZ, 2012, p. 132).
\end{abstract}

A autora, então apresenta uma hipótese geral para os "efeitos de ser testemunho" que se desdobram em duas sub-hipóteses. Como hipótese geral a autora parte do

\footnotetext{
${ }^{1}$ Lei Orgânica da Assistência.

2 "Contemplar a qualidade da vida laboral está intimamente vinculado como o cuidado da saúde de quem trabalha com o tema" (VELÁZQUEZ, 2012, p. 131).
} 
pressuposto que no encontro que ocorre entre profissional e usuário se estabelece um testemunho central a partir das narrativas de violência em que o usuário, sob efeito de confiança junto ao profissional ou a equipe, revela seu segredo. A primeira sub-hipótese parte da ideia que este encontro desencadeia um processo de identificação entre profissional e usuário, podendo afetar o curso do processo de atendimento de um lado, ou de outro, provocar um alto grau de estresse no profissional.

\begin{abstract}
Nos interesa destacar aquí los efectos de ser testigo de las violencias por las que se consultan, en concordancia con otros hechos que han sido estudiados, promotores de distintas formas de estrés laboral. Nos referimos a los fenómenos de burnout y de fatiga de compasión que constituyen estados consecuentes del involucramiento crónico en situaciones de ayuda a otros, emocionalmente muy demandantes. También a las situaciones capaces de desarrolhar estrés laboral como el mobbing, el acoso psicológico, el acoso sexual y el backlash entre otros que hemos descripto (VELÁZQUEZ, 2003a, p. 295 apud VELÁZQUES, 2012, p. 133).
\end{abstract}

A segunda sub-hipótese é que os profissionais que atuam na questão de gênero vivenciam tensão e conflito em função da tarefa a que estão vinculados. Tal sub-hipótese baseia-se na ideia de que o fato de escutar tantos relatos de violência motiva sua reprodução no ambiente de trabalho, fatos denominados pela autora de microviolências na prática.

Para evitar a reprodução de microviolências na prática, entre os membros da equipe, estratégias de apoio mútuo, terapias custeadas pelos próprios peritos e o investimento em lazer/entretenimento servem como condições de reprodução do sujeito para enfrentar um dia-a-dia nada ameno.

O fato de testemunhar é criar um novo saber e consequentemente um determinado poder na perspectiva de Foucault (1999; 2005). Estar diante de um profissional que atua dentro de uma proposição especializada, no caso, a violência sexual, leva o usuário a construir a ideia de que, a partir das narrativas, na reconstrução de lembranças, de dar voz a algo que estava silenciado, a uma equipe que confere no discurso prático total sigilo e confiança, que os relatos não serão publicizados, leva o usuário a crer na possibilidade de libertação, de saída, de se desarmar de uma situação de violência, na esperança de livrar-se dessa teia invisível.

Este encontro se estende para além da palavra, demonstrado em gestos, tonalidade da voz, em se colocar no lugar do outro.

Se testigo de esas narraciones no significa ser espectador pasivo de lo que cuenta una persona que fue violentada. Tampoco significa constituirse en participante activo de esa escena, sino que ese testigo tendrá que observar, comprender y hablar desde fuera de la escena violenta ( VELÁZQUEZ, 2012, 135).

Ser testemunho de um relato de violência sexual contra criança e adolescente, em contexto intra ou extrafamiliar, não é um trabalho simples. Faz-se necessário a criação de uma postura de distanciamento entre a palavra escutada e as cenas criadas no processo de reconstrução das narrativas. Se o profissional não consegue ou não tem respaldo 


\section{asusossunatempordilis}

institucional para exercitar esse distanciamento, os adoecimentos e o comprometimento em um intervenção adequada estarão presentes.

Sendo assim, estratégias, solidariedade entre os profissionais, ajuda por um profissional capacitado que dê a supervisão psicológica aos profissionais, a realização de trabalhos lúdicos têm sido as saídas buscadas por alguns profissionais. Destaque-se, ainda, que dentro da política de humanização e educação continuada no Sistema Único de Saúde (SUS), o município de João Pessoa (PB) e de Recife (PE) apresentam uma agenda de atividades dentro do projeto Cuidando do Cuidador, porém, a demanda por esse serviço, que cobre várias políticas setoriais (saúde, assistência, educação), é grande e não confere a todas as unidades de gestão um suporte necessário.

O afastamento que os profissionais de Serviço Social têm da educação continuada, ora inviabilizada pela questão da renda, ora pela precarização do trabalho, visto que o tempo livre, conquistado pela categoria com a redução da carga horária para 30 horas, hoje é substituído por novos postos de trabalho. Tal situação concorre para uma atuação operativa e técnica, diferente da proposição desenhada pelo Projeto Ético-Político da profissão, que se consolida no nosso Código de Ética, na lei que regulamenta a profissão e nas diretrizes curriculares que embasam o processo formativo.

As transformações do mundo do trabalho não deixam de fora o assistente social e sua condição também precarizada de atuação, que se expressa nos cortes dos gastos sociais, influindo diretamente nas políticas públicas, elemento de mediação entre Estado, capital, assistente social e usuários; na precarização dos postos de trabalho e na formação técnica deficitária que levam os assistentes a atuarem precariamente. A falta de formação adequada, a dificuldade de investimento por parte deste profissional em garantir complementações formativas, o pouco investimento das unidades de gestão em formação especializada vem colocar o profissional em situação de fragilização, provocando no mesmo um processo de adoecimento (ALVES, 2011). Tais condições têm rebatimento direto quando, na outra ponta do atendimento do assistente social, se encontra a criança e/ou o adolescente vítima de violência sexual.

Neste sentido, repensar o cotidiano dos assistentes sociais, com suas singularidades trazidas pelas demandas dos usuários, deve fazer parte do fazer profissional a partir da relação indissociável entre teoria e prática preconizada no processo de formação acadêmica.

\section{O ENFRENTAMENTO DA VIOLÊNCIA SEXUAL INTRAFAMILIAR E A AÇÃO EM REDE: INTENCIONALIDADE OU AÇÃO?}

A perspectiva da proteção integral nos leva a pensar numa ação em rede, sob olhares diferenciados e com saberes diferenciados. O próprio ECA/90, na sua indicação do atendimento da proteção integral, sinaliza para a criação de comunicabilidade entre os diversos segmentos de assistência à criança e à adolescência. Para isso, a compreensão da rede como um fenômeno das sociedades reticulares nos indica que a intervenção 
singular de qualquer política não garante um atendimento que venha a efetivar o que se denomina de proteção integral (ELIAS, 1994).

A ideia de rede está associada à articulação racional e política de esforços e recursos, mediante a ação conjugada e compartilhada de políticas, organizações, atores e forças, tanto públicas como sociais. O trabalho em redes e com redes pressupõe a superação da burocracia que engessa as instituições e atores sociais e se instaura mediante um processo dinâmico, ativo, efetivamente orgânico e relacional. Nessa perspectiva, os laços e parcerias não funcionam como convênios, mas como contratos dinâmicos, em movimento e conflito, para, no entanto, realizar objetivos em que cada parte potencializa recursos que juntos se tornam também mais eficientes (FALEIROS, 1998, p. 267 apud AMARO, 2011 p. 130).

No estudo, as redes são imprescindíveis no delineamento, enfrentamento e atuação nos casos de violência sexual. Chegar até a vítima sem o apoio de uma atividade em rede ou atuar após a chegada da denúncia não se concretiza em uma ação eficaz sem o mecanismo do trabalho em rede.

Vale destacar que, no caso do atendimento à infância e adolescência sob violação sexual, há dois mecanismos de atuação: as redes de solidariedade e comunitária e as redes de proteção (CARVALHO, 2003).

\begin{abstract}
Para Aguiar, tanto a organização quanto a análise de uma rede social devem considerar dois aspectos que, a seu ver, são indissociáveis. O primeiro seria a estrutura, em que os nós representam os indivíduos, os elos representam a união dos nós, os tipos de vínculos representam a classificação das relações entre os nós e os papéis exercidos por cada nó qualificam as interpelações. O segundo seria a dinâmica, na qual as relações espaço-temporais devem ser levadas em conta, como processo no qual se observa, por exemplo, o padrão de fluxo de informação ocorrido entre os nós, o ritmo em que ocorre as interconexões ou o fluxo de informação, os graus de participação de cada integrante da rede e os efeitos que essa participação pode proporcionar aos membros da rede e os efeitos que essa participação pode proporcionar aos membros da rede e a rede com um todo (CARVALHO, 2003, p. 11-4 apud FURINI, 2011, p. 170).
\end{abstract}

Um dos condicionantes "[...] do mundo atual é a exigência de fluidez para a circulação de ideias, mensagens, produtos ou dinheiro, interessando aos atores hegemônicos. A fluidez contemporânea é baseada nas redes técnicas, que são um dos suportes da competitividade. [...] A fluidez é, ao mesmo tempo, uma causa, uma condição e um resultado" (SANTOS, 2006, p. 185).

Mas a fluidez não é uma categoria técnica, mas uma entidade sociotécnica. Ela não alcançaria as consequências atuais, se, ao lado das novas inovações técnicas, não estivessem operando novas normas de ação, a começar, paradoxalmente, pela chamada desregulação. A economia contemporânea não funciona sem um sistema de normas, adequadas aos novos sistemas de objetos e aos novos sistemas de ações, e destinados a provê-los de um funcionamento mais preciso. $\mathrm{Na}$ realidade, trata-se de normas constituídas em vários subsistemas interdependentes, cuja eficácia exige uma-vigilância contínua, assegurada por uma legislação mundial, tribunais mundiais e uma polícia mundializada. Ao contrário do imaginário que a acompanha, a desregulação não suprime as 


\section{asusosesvatempordilis}

normas. Na verdade, desregular significa multiplicar o número de normas (SANTOS, 2006, p. 186).

A falta de feedback, muitas vezes encontrada na resolutividade de casos de violência sexual, fragiliza o trabalho em rede e quebra a compreensão de uma atenção integral. Assim, existe um discurso com amparo legal que estimula e subsidia a atuação e proteção integral, garantindo a ação delimitada a partir dos recursos encontrados no território, mas sua operacionalização e o fluxo contínuo de comunicação reforçam a ação focalizada e desintegrada com que os componentes da rede estão envolvidos. A falta de retorno às demandas encaminhadas esbarra na falta de estrutura material e pessoal reduzida e com sobrecarga de trabalho, além da identificação e envolvimento dos profissionais da assistência com questões burocráticas. Dessa forma, o caminhar em fluxo contínuo se perde no espaço e no território.

Os profissionais que buscam nas redes respaldo para seus casos se deparam com a inércia e os gargalos. Sem a fluidez necessária para solucionar ou dar andamento aos processos de violação sexual, associado a problemas de infraestrutura e de gestão, os profissionais se veem compelidos a atuarem dentro de um limite de ação.

\section{CONCLUSÃO}

Integrar uma equipe que atue como assistente à violência sexual não é uma escolha fácil. Segundo Palmonari e Zani (1990, p. 90 apud Velázquez, 2012, p. 105), alguns condicionantes se fazem necessários, dentre eles: ser um lugar de pertencimento e referência, ou seja, um ponto de apoio para o desenvolvimento da prática profissional; representar um campo de trabalho para o exercício e realização profissional e pessoal; representar um espaço de troca e intercâmbio de saberes. Mas, dentre os condicionantes elencados por Velázquez, um nos chamou atenção: ser "Um ponto de apoio para conter e/ou neutralizar os efeitos psicofísicos que são provocados pela tarefa da violência" (PALMONARI; ZANI, 1990, p. 90 apud VELÁZQUEZ, 2012, p 105).

O adoecimento, nos postos de trabalho, dos técnicos que atuam com violência é uma constante. Alves (2011), em seu trabalho sobre Trabalho e Subjetividade - o espírito do toyotismo na era do capitalismo manipulatório, descreve o processo de perda da subjetividade do trabalhador e sua repercussão no cotidiano laboral com processos constantes de adoecimento. No campo específico da violência sexual, nesse estudo, os profissionais entrevistados apontam a falta de apoio institucional ao trabalho específico com as vítimas, no que tange ao suporte emocional, na perspectiva do cuidar do cuidador tem levado ao comprometimento da saúde desses trabalhadores.

Até porque, atuar com a dor do outro, na qualidade de testemunho indireto do ato abusivo sexual, não é tarefa fácil para nenhum profissional, requerendo teste um suporte emocional para que tal realidade não imprima um adoecimento físico e/ou metal dos profissionais envolvidos.

\footnotetext{
3 Un punto de apoyo para contener y/o neutralizar los efectos psicofísicos que suele provocar la tarea en violência (PALMONARI; ZANI, 1990, p. 90 apud VELÁZQUEZ, 2012, p. 105).
}

Temporalis, Brasília (DF), ano 18, n. 35, jan./jun. 2018. 


\section{REFERÊNCIAS}

ALVES, Giovanni. Trabalho e Subjetividade: o espírito do toyotismo na era do capitalismo manipulatório. São Paulo: Boitempo, 2011.

AMARO, Sarita. Crianças vítimas de violência: das sombras do sofrimento à genealogia da resistência: uma nova teoria científica. 2. ed. Porto Alegre: EDIPUCRS, 2011.

ARRAZOLA, Laura Susana Duque. O cotidiano sexuado de meninos e meninas em situação de pobreza. In: FELICIA, Reicher Madeira. Quem mandou nascer mulher?: estudo sobre crianças e adolescentes pobres no Brasil. Rio de Janeiro: Record Rosa dos Ventos, 1997.

AZEVEDO, Maria Amélia; GUERRA, Viviane Nogueira de Azevedo. (Orgs.). Crianças vitimizadas: a síndrome do pequeno poder. São Paulo: Iglu, 1989, 2007.

BRASIL. Presidência da República. Lei nº 12.435, de 6 de julho de 2011. Altera a Lei no 8.742, de 7 de dezembro de 1993, que dispõe sobre a organização da Assistência Social. Brasília (DF), 2011. Disponível em: < http://www.planalto.gov.br/ccivil_03/_ato2011/2014/2011/lei//12435.htm >. Acesso em: 17/03/2018.

BRASIL. Presidência da República. Lei n 8.742, de 7 de dezembro de 1993. Dispõe sobre a organização da Assistência Social e dá outras providências. Brasília (DF), 1993. Disponível em: <http://www.planalto.gov.br/ccivil_03/Leis/L8742compilado.htm>. Acesso em: 10 set. 2017.

CARVALHO, Maria do Carmo Brant. A ação em rede na implementação de políticas e programas sociais públicos. Revista de Información del Tercer Sector, Madrid, abr. 2003. Disponível em: <http://www.lasociedadcivil.org/wpcontent/uploads/2014/11/a_ao_em_rede_na_implementao.pdf >. Acesso em: 10 ago. 2017.

ELIAS, Nobert. A sociedade dos indivíduos. Rio de Janeiro: Jorge Zahar, 1994.

FERREIRA, Kátia Maria. Violência Doméstica/Intrafamiliar contra crianças e adolescentes. In: SILVA, Lígia Maria Pereira da. Violência doméstica contra crianças e adolescentes. Recife: Edupe, 2002.

FOUCAULT, Michel. Microfísica do Poder. Belo Horizonte: Graal, 1999.

FOUCAULT, Michel. Vigiar e punir: história da violência nas prisões. 24.ed. Petrópolis: Vozes, 2005.

FURINI, Luciano Antonio. Redes sociais de proteção integral à criança e ao adolescente: falácia ou eficácia. São Paulo: UNESP, 2011.

GUERRA, Viviane Nogueira de A. (Orgs.). Infância e violência doméstica: fronteiras do conhecimento. 2. ed. São Paulo: Cortez, 1998. 


\section{aвuso sexualtemPPOCOllis}

SANTOS, Milton. A natureza do espaço: técnicas e tempo, razão e emoção. São Paulo: Universidade de São Paulo, 2006.

VELÁZQUEZ, Susana. Violencias y famílias implicancias del trabajo profissional: el cuidado de quienes cuidan. Buenos Aires: Paidós, 2012. 